\title{
Should women with postcoital bleeding be referred for colposcopy?
}

Batish $A^{1}$, Sathiyathasan $S^{1}$

${ }^{1}$ Kings College Hospital NHS Trust, London

Received: 13-Jun-2016; Accepted: 14-Aug-2016

\begin{abstract}
Electronic searches of literature published between 1980 and 2014 were undertaken using MEDLINE, Embase, CINHAL, and the Cochrane Database of Systemic reviews. Search items included: post coital bleeding, colposcopy, cervical cancer. Postcoital bleeding remains a cardinal warning sign of lower genital tract cancer and it is important to remember that it can also occur in the absence of cancer. In the vast majority of cases, there will be no sinister pathological abnormality. The common causes are usually benign conditions such as cervical ectopy and benign cervical polyps. Only a small number of women with PCB will have invasive disease of the lower genital tract.
\end{abstract}

\section{INTRODUCTION}

Postcoital bleeding (PCB) refers to spotting or bleeding that occurs after intercourse and is not related to menstruation. The point prevalence ranges from 0.7 to $9.0 \%$ with one report indicating that the annual cumulative incidence is $6 \%$ among menstruating women. ${ }^{1}$ In women under the age of 35 years, the most important cause to exclude is chlamydial infection, while in women over the age of 35 years it is cervical cancer. Postcoital bleeding is commonly caused by cervical or endometrial polyps, cervicitis as a result of chlamydia or gonorrhoea and vaginitis associated with trichomoniasis or candidiasis. Endometritis in the presence of an intrauterine contraceptive device (IUCD) can occasionally cause postcoital bleeding. This symptom is rarely caused by cervical intraepithelial neoplasia. ${ }^{2}$

\section{METHODS}

Electronic searches of literature published between 1980 and 2014 were undertaken using MEDLINE, Embase, CINHAL, and the Cochrane Database of Systemic reviews. Search items included: post coital bleeding, colposcopy, cervical cancer.

\section{RESULTS}

There are wide variations in the management of women with postcoital bleeding in the UK probably due to gynaecology, oncology, Colposcopy and cervical

\section{CORRESPONDENCE}

Dr Avni Batish

Princess Royal University Hospital, Kings College Hospital NHS

Trust, Kent, BR6 8ND, UK

E mail: a.batish@nhs.net

Phone: 01689863000 pathology services not necessarily coming together in most of the health care setting. ${ }^{3}$ NICE guidelines state that women with postcoital bleeding should have full pelvic examination, including speculum examination, by the primary health care professional and those patients who have clinical features suspicious of cervical cancer should be referred urgently. ${ }^{4} \mathrm{~A}$ cervical smear test is not required before referral, and a previous negative smear result is not a reason to delay referral to the gynaecology department.

Similarly, the National Health Service cervical screening programme in the UK recommends that women presenting with symptoms of cervical cancer- such as postcoital bleeding (particularly in women over 40 years) - should be referred for gynaecological examination and onward referral for colposcopy if cancer is suspected. ${ }^{5}$ Examination should be performed by a gynaecologist experienced in the management of cervical disease (such as a cancer lead gynaecologist). The equivalent Scottish guidelines recommend urgent referral of women $>35$ years with persistent ( $>4$ weeks) postcoital bleeding and early referral for women with repeated unexplained postcoital bleeding. ${ }^{6}$ The guidelines for referral for suspected Cancer published by Department of Health in the United Kingdom defined criteria for referral only; urgent referral (within 2 weeks) for PCB more than 4 weeks in women $>35$ years of age, and early referral (within 4-6 weeks) in all other cases of repeated unexplained PCB. ${ }^{7}$

Postcoital bleeding mainly comes from surface lesions of the genital tract to include cervical polyps, cervicitis, ectropion, cervical intra-epithelial lesion 
(CIN), or carcinoma. ${ }^{8}$ The majority of women presenting to their primary care physician with the complaints of postcoital bleeding will be found to have no obvious underlying cause for their bleeding based on history, examination, or laboratory investigation. ${ }^{9}$ Nevertheless, the reassuring aspect is that $60 \%$ of naturally menstruating women with postcoital bleeding will have spontaneous resolution of symptoms within six months. ${ }^{1}$ Half of these women will maintain resolution for two years. ${ }^{1}$

A retrospective study by Rosenthal et $\mathrm{al}^{9}$ of 314 women with PCB showed 12 cases of invasive cancer (3.8\%): ten were cervical or vaginal cancers and two endometrial cancers. Eight out of the ten cervical / vaginal cancers were clinically apparent. Four of these ten had normal smears before being referred for further investigation of PCB. Two of those were visible only with the aid of the colposcope. Thus $0.6 \%$ (2/314) of women attending the gynaecology service with $\mathrm{PCB}$, and a normal looking cervix and normal smear had invasive cancer of the cervix. Cervical intraepithelial neoplasia was found in 54 women $(17.2 \%)$. Nineteen of the 66 women $(28.8 \%)$ with cancer/CIN had a normal or inflammatory cervical smear. 15 women $(5 \%)$ had cervical polyps, 18 has had HPV, 49 inflammatory changes or metaplasia, and no explanation was found in 155 women.

Anorlu et $\mathrm{al}^{10}$ report a series of 885 women in a clinic in Lagos Nigeria 1998-1999. Dyskaryosis was significantly higher in symptomatic compared to asymptomatic cases $(6.1 \%$ vs. $3.4 \% \mathrm{p}<0.01)$ with $9.3 \%$ of patients with postcoital bleeding demonstrating dyskaryosis.

A case series ${ }^{11}$, a study of 248 women referred with PCB over a 5-year period to the gynaecology department at Southend Hospital Prittlewell Chase, Westcliff-on-sea, Essex, UK; reported no cases of lower genital tract cancer following PCB. Twelve women $(4.8 \%)$ had CIN, 24 women $(9.6 \%)$ had polyps (endometrial and cervical), and 61 (24.6\%) had cervical ectopy.

Another retrospective study of 142 women with postcoital bleeding reported a total of $27(19 \%)$ had cervical intraepithelial neoplasia (CIN) out of which there were $15(10.6 \%)$ cases of high-grade disease (CIN2 and CIN3). ${ }^{12}$ Out of the 102 women who had a negative smear within the three years prior to referral, 20 had CIN (19.6\%) and ten of those were high grade CIN (eight with CIN 2 and two with CIN3) (9.8\%). In this cohort there were no cases of invasive cancer of lower genital tract.

In another retrospective study ${ }^{13}$ the prevalence of CIN was $9 \%$ but high grade CIN in only $2.2 \%$ and mostly this was CIN2. The prevalence of invasive cancer was zero. A similar retrospective study found high grade CIN in $1.6 \%(1 / 64)$ of patients referred to colposcopy with postcoital bleeding and negative smears, in which no cases of cancer were detected. ${ }^{14}$ Similarly, another retrospective study of 87 women with postcoital bleeding and negative smears found $\mathrm{CIN}$ in $6.9 \%$ \& there were no cases of invasive cancer. ${ }^{15}$

\section{CONCLUSIONS}

Postcoital bleeding remains a cardinal warning sign of lower genital tract cancer and it is important to remember that it can also occur in the absence of cancer. In the vast majority of cases, there will be no sinister pathological abnormality. The common causes are usually benign conditions such as cervical ectopy and benign cervical polyps. Only a small number of women with $\mathrm{PCB}$ will have invasive disease of the lower genital tract.

\section{DISCLOSURE}

The authors report no conflicts of interest in this work.

No violation of human rights and safety.

Funding: Nil

\section{REFERENCES}

1. Shapley M, Jordan K, Croft PR. An epidemiological survey of symptoms of menstrual loss in the community. British Journal of General Practice. 2004;54(502):359-363.

2. Trends in Urology, Gynaecology \& Sexual Health. 2008;13(4). Article first published online: 25 JUL 2008

3. Khattab AF, Ewies AA, Appleby D, Cruickshank DJ. The outcome of referral with postcoital bleeding (PCB). J Obstet Gynaecol. 2005; 25: 279-282.
4. NICE Referral guidelines for suspected cancer. Clinical guideline 27. NICE. London. 2005.

5. NHSCSP Publication No. 20. Colposcopy and Programme Management: Guidelines for the NHS Cervical Screening Programme. NHSCSP.2010.

6. Scottish Executive. Scottish Referral Guidelines for Suspected Cancer. 2007 
7. Department of Health. NHS Executive Guidelines for referral for suspected cancer. April, 2000.

8. Fraser IS, Petrucco OM. Management of intermenstrual and postcoital bleeding, and an appreciation of the issues arising out of the recent case of O'Shea versus Sullivan and Macquarie pathology. Australian and New Zealand Journal of Obstetrics and Gynaecology. 1996;36(1): 67-73.

9. Rosenthal AN, Panoskaltsis T, Smith T, Soutter WP. The frequency of significant pathology in women attending a general gynaecological service for postcoital bleeding. British Journal of Obstetrics and Gynaecology. 2001;108(1):103-106.

10. Anorlu RI, Abdul-Kareem FB, Abudu OO, Oyekan TO (2003) Cervical cytology in an urban population in Lagos, Nigeria. J Obstet Gynaecol. 2003; 23: 285-288.

11. Selo-Ojeme DO, Dayoub N, Patel A, Metha M. A cliniciopathological study of postcoital bleeding. Arch Gynecol Obstet. 2004; 270: 34-36.
12. Abu J, Davies Q, Ireland D. Should women with postcoital bleeding be referred for colposcopy? J Obstet Gynaecol. 2006; 26: 45-47.

13. Obeidat RA, Saidi SA. Prevalence of High-Grade Cervical Intraepithelial Neoplasia (CIN) and Cervical Cancer in Women with Post- Coital Bleeding (PCB) and Negative Smear: A Retrospective Study. Gynecol Obstet. 2012; 2:127. doi:10.4172/2161-0932.1000127

14. Ray P, Kaul V. Prevalence of high-grade squamous intraepithelial neoplasia (HiSIL) in symptomatic women referred to the colposcopy clinic with negative cytology. Arch Gynecol Obstet. 2008; 277: 501-504.

15. Sahu B, Latheef R, Aboel Magd S. Prevalence of pathology in women attending colposcopy for postcoital bleeding with negative cytology. Arch Gynecol Obstet. 2007; 276: 471-473. 